\title{
A Methodological Review of Systematic Literature Reviews in Higher Education:
}

\section{Heterogeneity and Homogeneity?}

\begin{abstract}
The field of higher education research has bourgeoned in the past decades, addressing a wide range of topics. Being in a rapidly expanding and interdisciplinary field of research, higher education scholars have demonstrated exigency for aggregating research findings to map the research landscape, identify future research directions, and bridge the research-practice divide. In this connection, systematic literature reviews have been carried out to consolidate research findings. With a proliferation of systematic literature reviews in higher education, the aim of this meta, methodological review is to provide a state-of-the-art systematic literature review methodologies in the field of higher education. Adhering to the exploratory nature of this study, this review analyses systematic literature reviews published in 16 toptiered international journals in higher education $(n=160)$. Through qualitative research synthesis using thematic analysis and informed by grounded theory, a methodological framework comprising six stages and 20 steps is developed, which might help to instigate methodological dialogue between researchers when it comes to conducting systematic literature reviews. A handy checklist for conducting and evaluating systematic literature reviews in higher education is created.
\end{abstract}

Keywords: systematic review; scoping review; research synthesis; methodology; higher education

\section{Introduction}

Over the past few decades, research into higher education has witnessed a rapid expansion (Tight, 2018). As new evidence is accumulating at an unprecedented speed, criticism is directed to the non-cumulative nature of higher education research (Hargreaves, 1996). Heterogeneous research designs and a lack of conclusive findings make it difficult for 
education providers to make use of research findings and improve practice (Tranfield, Denyer, \& Smart, 2003). With the ultimate aim to provide rigorous, high-quality evidence that informs practice and policy, it has been proposed that the present focus of higher education research should be on summarizing and synthesizing the available research outputs, rather than undertaking new studies (Bearman et al., 2012; Tight, 2018; 2019). Research synthesis is a collective term for methods used for summarising, integrating and cumulating findings (Davies, 2000). There has been a proliferation of types of research synthesis; in addition to those commonly practised (e.g., systematic review), emergent forms of research synthesis are noted (e.g., evidence map (Miake-Lye et al., 2016)). Research synthesis not only assesses what has been learnt and produces useful generalisations for decision-makers, but also identifies central research issues and gaps for future research (Cooper \& Hedges, 1994).

Among the different approaches to research synthesis, systematic literature review has been considered a relevant and effective means to sum up research evidence in higher education research (Bearman et al., 2012; Davies, 2000; Evans \& Benefield, 2001; Tranfield et al., 2003). Unlike traditional literature reviews that report studies in an idiosyncratic fashion, systematic literature reviews are regarded as a "fundamental scientific activity" (Mulrow, 1994, p. 597), synthesizing evidence in a transparent, comprehensive and systematic manner. The field of medicine and healthcare has a long tradition of using systematic literature reviews to summarize intervention effectiveness supported by Cochrane Collaboration. On the other hand, organisations like Campbell Collaboration and EvidenceInformed Policy and Practice in Education Center (EPPI-Center) have tried to adjust the approach and develop protocols for conducting systematic literature reviews on educational research (Evans \& Benefield, 2001; Gough et al., 2017). Yet according to Bearman et al. (2012), the response in higher education is less favourable in contrast to the medical field, 
with much fewer systematic literature reviews published in higher education journals. Even among the systematic literature reviews that have been published, there is little agreement regarding the appropriate methodology to be used (Tranfield et al., 2003); such difference is especially noticeable in the use of methodological jargon.

It can be seen from the above that, albeit its usefulness to inform research and practice, systematic literature review has not been as widely practised in higher education as in other fields, partially due to the divergent understanding of methodologies and related jargon. Because of the increasing number of systematic literature reviews in higher education published in the past years (see Table 4 in Section 2.2), it is an opportune time to review the state-of-the-art vis-à-vis methodologies employed in these reviews. The paper is a metareview on the methodology section of 160 systematic literature reviews published in 16 leading international higher education journals listed in Tight (2018). We conducted a rigorous qualitative research synthesis, with data synthesized using grounded theory methodology (Charmaz, 2014), on the methodology section of these reviews; the outcome of analysis is a generic methodological framework for conducting systematic literature reviews on higher education research and a handy checklist (Appendix B).

\section{Literature Review}

\section{Systematic Literature Reviews in Higher Education}

In this paper, systematic literature review refers to a "protocol-driven and qualityfocused approach" to synthesize research evidence to inform practice and policy using a rigorous and replicable methodology (Bearman et al., 2012, p. 625). Such systematic methodology can usually be broken down into several stages, namely, scoping, searching, screening, coding, mapping, appraising, synthesizing, and communicating (Gough et al., 2013, p.11). Following Bearman et al.'s (2012) definition, we consider the systematic synthesis of both quantitative and qualitative data (using meta-analysis and qualitative 
research synthesis approaches) systematic literature reviews ${ }^{1}$. The adoption of this more encompassing definition of systematic literature review is also grounded on a realist consideration, that some systematic literature reviews in higher education synthesise both quantitative and qualitative data (e.g., Cook et al., 2010; Nismith et al., 2015).

Systematic literature reviews in higher education are sometimes referred to as scoping reviews. In practice, systematic literature reviews and scoping reviews are almost always used interchangeably, with the latter also defined as the use of "a rigorous and transparent method" to synthesize research findings (Pham et al., 2014, p. 372). In fact, scoping reviews are sometimes conducted as a preliminary study of systematic literature reviews when the topic or research area in focus "has not yet been extensively reviewed or is of a complex or heterogeneous nature" and "types of evidence available" remain unclear (Tricco et al., 2016, p.2). A scoping review maps the nature, type, and state of literature (original research, grey literature, discursive literature) on any given topic, is broader in scope, and may not include critical appraisal of the reviewed literature. On the other hand, systematic literature reviews focus on research questions, almost always only include primary or original research, and must include critical appraisal and synthesise the findings considering the quality rating of the studies (c.f. Munn et al., 2018). In this review, scoping reviews were included in the search.

In the context of higher education research, systematic literature reviews are not an umbrella term used to denote all types of secondary research. Other types of secondary research which are inherently different from systematic literature reviews include, for example, bibliometric reviews and historical reviews. Bibliometric reviews are reviews which, albeit the employment of transparent and replicable research methodologies, focus on

\footnotetext{
${ }^{1}$ We acknowledge that some may conceptualise meta-analysis as a discrete form of review from systematic review (e.g., Grant \& Booth, 2009), but our more inclusive definition is also advocated by some as a more practical definition (e.g., Bearman et al., 2012; Khan et al., 2003).
} 
bibliographical information of scholarly publications, including demographics of authors, citation patterns, and research trends (e.g., Hallinger \& Kovačević, 2019). Historical reviews, which have been a long-standing review genre in higher education, adopt a descriptive and thematic approach to trace the development of a specific research field or topic. The most notable difference between historical reviews and systematic literature reviews is that the former does not follow a pre-determined set of search protocol, meaning that studies included in historical reviews are usually selected based on the reviewers' preference (e.g., Lee, 2007).

Through a comprehensive search on the systematic literature reviews published in prestigious international journals in the field of higher education, as listed in Tight (2018), from Jan 2000 to October 2018 (refer to Section 3 for details of methodology), a total of 160 systematic literature reviews were identified. Tables 1 and 2 provide the breakdowns of the number of systematic literature reviews published in each of these journals and in each year respectively. Figure 1 shows the locations where the reviews were conducted. The complete bibliographical information of the 160 reviews is uploaded as online supplementary information (Appendix A).

\section{[Table 1 here]}

[Table 2 here]

[Figure 1 here]

\section{Methodological Papers on Systematic Literature Reviews}

In the past decade, a number of methodological papers were published which outline the methodological steps recommended for conducting systematic literature reviews, mainly in the field of healthcare (Armstrong, Hall, Doyle, Waters, 2011; Bearman et al. 2012; Furlan, Pennick, Bombardier, \& van Tulder, 2009; Gough, Thomas, \& Oliver, 2012; Grant \& Booth, 2009; Pham et al., 2014). For example, the Cochrane Back Review Group editorial and advisory boards published a revised methodological guidelines on conducting systematic 
literature reviews of trials of treatments for neck and back pain (Furlan et al., 2009). This set of guidelines are categorised into seven steps: objectives, literature search, inclusion criteria, risk of bias assessment, data extraction, data analysis, and review updates. For each methodological step, this document offered mandatory criteria and optional suggestions. This report differed from its previous version in a sense that the 2009 edition introduced a new mechanism to determine the quality of evidence presented in the reviewed clinical studies. Moreover, "updating reviews", an additional methodological step was introduced. Also focusing on the field of healthcare, Grant and Booth (2009) identified 14 review types in the discipline, presented the methodologies used in these reviews, and critically evaluated their respective strengths and limitations. In the discipline of public health, Armstrong et al. (2011) provided a succinct walkthrough of the recommended steps for conducing scoping reviews. These steps include: formulate research question(s), select related studies, chart data, report results, and consulting stakeholders (optional). To the best of the authors' knowledge, Bearman et al. (2012) is the first and only systematic literature reviews methodological paper published in higher education journals ${ }^{2}$. In their paper, Bearman et al. (2012) compared systematic literature reviews with narrative reviews and analysed methodology used in three systematic literature reviews in higher education; their commentary ended with a critical examination of the affordances and limitations of systematic literature reviews in higher education. In the same year, Gough and his associates (2012) categorized types of systematic literature reviews according to their aims, approaches, structure, components, breadth and depth of the reviews. They concluded their commentary by advocating the use of consistent terminology so that systematic literature reviews methodology can be further developed. Most recently, Pham et al. (2014) conducted a scoping review to provide a general description of topics, methodology, and findings of 344 scoping reviews published between

\footnotetext{
${ }^{2}$ Another paper, Tight (2019), also focused on systematic literature reviews and meta-analysis in higher education; however, the focus of this paper is on the topics covered in these two types of reviews rather than the methods.
} 
1999 and 2012. They found that conducting a scoping review is an arduous process, with the longest study completion time being 20 months; the majority of the scoping reviews concerned a health-related topic and over half of the scoping reviews adopted a pre-existing methodological framework.

In view of the above, there are a dearth of methodological papers on systematic literature reviews in higher education. The impetus for reviewing systematic literature review methodologies rests on the fact that higher education is a highly disjointed academic field, which MacFarlane (2012) described as "the higher education research archipelago" (p.129). MacFarlane (2012) argued that higher education research can be broadly divided into two strands: policy-related and teaching/learning-related, separated by the "sea of disjuncture", preventing communications between scholars in the two strands of higher education research because of the lack of a common academic language (p. 129). Extending the discussion on higher education as a disembodied field to research methodologies, Tight (2013) contended that methodologies used in conducting research in an academic discipline are what give a research field its identity. According to Tight (2013), higher education should draw upon strengths and collective wisdom of various sub-fields, which will develop higher education as an "academic discipline" (p.137). What Tight (2013) proposed is not a unification of higher education research; rather, it is a proposition of a more balanced view of higher education as "a field of study, researched from a number of disciplinary perspectives" (p. 138), which can be achieved through the development of a dialogic community of scholars, and clarification of data collection and analysis standards. Following this train of thought, higher education research methodologies, including those of systematic literature reviews, have to achieve a certain degree of standardization, for example, in the areas of naming conventions, without which often results in confusions and ineffective 
subtle difference of systematic literature reviews and scoping reviews) (Brew, 2003). At the same time, it must be acknowledged that higher education researchers come from different backgrounds, some working in education departments or research centres while others in their respective disciplines (e.g., social sciences, medicine), leading to heterogeneous methodological traditions and cultures (Tight, 2004; Välimaa, 1998). This methodological review is built on this realist view that higher education is one academic discipline with numerous methodological traditions, which warrants a need to celebrate methodological heterogeneity while maintaining as much homogeneity as possible in systematic literature reviews. The methodological framework presented in this review is the outcome of an inductive analysis of methodological stages and steps (each methodological stage can contain numerous steps) of 160 systematic literature reviews in leading higher education journals, presenting a coherent methodological framework using consistent terminologies while addressing variations in each methodological stage.

\section{Methodology}

A scoping review methodology based on the framework by Arksey and O’Malley (2005) is used (Table 3). A qualitative research synthesis is conducted using thematic analysis (Braun \& Clarke, 2006) to collate the methodological procedure of systematic literature reviews undertaken in the field of higher education. This bottom-up methodological framework draws on grounded theory in the data synthesis stage, a research methodology which "takes a systematic inductive, comparative, and interactive approach to inquiry and offers several open-ended strategies for conducting emergent inquiry", eventually resulting in the development of a "theory" (Charmaz, 2008, p. 156). Charmaz (1996) summarizes the logic of grounded theory clearly:

That means you start with individual cases, incidents or 
experiences and develop progressively more abstract conceptual categories to synthesize, to explain and to understand your data and to identify patterned relationships within it. You begin with an area to study. Then, you build your theoretical analysis on what you discover is relevant in the actual worlds that you study within this area. (pp.

"Theory" in grounded theory refers to both "substantive theory" (a theory based on existing literature) and "grounded/formal theory" (a theory that is based on data in the current study). It is a misconception that "theory" (i.e., a systematic observation of phenomena or practices) in grounded theory is purely derived from data. In fact, Glaser and Strauss (1967) contended that "although formal theory can be generated directly from data, it is more desirable, and usually necessary, to start the formal theory from a substantive one" (p.79). This semi-inductive view of grounded theory matches the intention of this methodological review, which, as argued before, is to capture the heterogeneity and homogeneity of methodological practices of systematic literature reviews in higher education. Arksey and O’Malley's (2005) methodological framework which guides this review is a "substantive theory", offering consistency and structure to enable meaningful analysis and comparison, resulting in the methodological stages of the bottom-up framework (see bolded headings in Figure 3). At the same time, "grounded theory" which is generated from iterative comparison amongst the included systematic literature reviews result in steps within each methodological stage which capture the complexity and variety of systematic literature reviews practices.

[Table 3 here]

\section{Identifying the Research Question}

The purpose of this methodological review is to develop a generic framework for conducting 
systematic literature reviews published in reputable higher education journals. The present review is thus guided by the following research question: What are the methodological stages and steps adopted by systematic literature reviews published in high-ranking higher education journals?

\section{Identifying and Selecting Relevant Studies}

As we hope to base our framework on reviews that make effective use of systematic literature review methodology, the data sources were limited to 28 key journals in the field of higher education, following the list provided by Tight (2018) (refer to Table 3). Tight (2018) developed the list based on a rigorous assessment of the years of publishing, size of outputs and ranking of the journal. In this connection, the journals included in the list are believed to provide good-quality systematic literature reviews in higher education. Another indicator of quality of these included reviews is that they all exhibit key features of a fine systematic literature review: scoping, searching, screening, coding and mapping, appraising, synthesizing, and communicating (Gough et al., 2013). For the convenience of searching, the reviews were all searched and obtained on the journal's websites.

The initial search, which was conducted by Author 2 in October 2018, began with general search terms which are considered relevant to systematic literature reviews: "scoping review", "systematic review", "research review" and "review". Studies were included if their titles contain "systematic reviews" or "scoping reviews". If the type of review was not specified in the title, the reviewer would skim the abstract of the article to determine whether the use of a systematic literature reviews methodology is indicated in the descriptions of research purpose, search strategies or data analysis process. There were no search restraints on the topic during the search because the focus is on methodologies. This exhaustive approach to literature search was adopted because the focus of a scoping review is to account for breadth (Arksey \& O’Malley, 2005). After the initial screening and the removal of a 
duplicated record, 202 reviews were obtained.

\section{[Figure 2 here]}

To further assure the relevance of the selected studies, the abstract and methodology sections of each included reviews were then subject to a second level of screening by Author 1 and Author 2 independently. The study would be included if it exhibits features of sound systematic literature reviews vis-à-vis their methodology including scoping, searching, screening, coding and mapping, appraising, synthesizing, and communicating (Gough et al., 2013). The screening criteria were agreed between the two reviewers beforehand, and the reviewers discussed any uncertainties or disagreements related to study selection through constant communications in the forms of meetings, emails, WhatsApps, and phone calls. The second screening eliminated 35 studies that failed to meet the eligibility criteria, resulting in 167 reviews. However, the research team failed to access seven reviews because their universities do not subscribe to those journals, rendering a total of 160 reviews selected eventually for data extraction. The process of study selection follows the Preferred Reporting of Items for Systematic Reviews and Meta-analyses (PRISMA) Statement (Moher et al., 2009), which is illustrated by Figure 2 .

\section{Extracting Data}

Data extraction was performed on the selected 160 reviews, focusing on the methodology section, by Author 2 and validated by Author 1. A data extraction form was developed by the two reviewers to chart the study characteristics such as publication year, location, terminology used, frameworks used to guide the methods, and the methodological steps adopted to conduct the reviews. Data extraction was first performed by Author 2, who has a master's degree in education and experience in conducting systematic literature reviews, and verified by Author 1, who is an academic with a track record of publications in higher education and is an experienced systematic reviewer. Verification took place by having 
Author 1 read the extracted information alongside the methodology sections of original articles. When necessary, Author 1 made changes on the documents using track changes. To confirm the changes, the two reviewers discussed the changes in person, via email, or on phone until a consensus was reached.

\section{Synthesizing Data}

Thematic analysis (TA) is used to conduct qualitative research synthesis on the methodology section of the 160 systematic literature reviews (Braun \& Clarke, 2006). Qualitative research synthesis refers to synthesis of research findings from different studies using various qualitative analysis methods, including grounded theory, meta-ethnography, thematic analysis (Booth et al., 2016). Specifically, TA is a "method for identifying, analysing, organising, describing, and reporting themes found within a data set" (Nowell et al., 2017, p. 2). In this review, we followed the six-phase TA framework proposed by Nowell et al. (2017): familiarising with data, generating initial codes, identifying themes, reviewing themes, defining and naming themes, and reporting the results (p. 4). Following this six-stage TA framework, specific steps adopted to synthesize the methodological procedures are outlined in Table $2^{3}$. The synthesis process in Table 4 was done independently by Author 1 and Author 3. Throughout the process, constant communications were made between the two authors using Skype to resolve disagreements regarding coding and synthesis of codes.

\section{[Table 4 here]}

\section{Consulting with Experienced Reviewers}

The consultation stage involved two stakeholders: both are senior researchers who have years of experience doing systematic literature reviews (a full professor based in New Zealand and an associate professor in the UK). These two senior academics found the framework useful; in particular, the full professor commented: "this is important work that

\footnotetext{
${ }^{3}$ A detailed coding scheme comprising methodological stages, methodological steps, number of systematic literature reviews, and coded examples from original reviews can be found in Appendix C (online supplementary information).
} 
needs to be carried out more frequently in our field and that has the potential significantly to inform both research and its practical applications". Additionally, both provided suggestions for further enhancement of the framework in our future work, including conducting a Delphi study as a follow-up to achieve stakeholder consensus about the elements of systematic literature reviews which are deemed the most crucial. Purposive sampling was employed when selecting the stakeholders who are experienced reviewers to offer comments on the methodological framework; however, it must be noted that there is a degree of randomness in the selection process, limited by the reviewers known to the authors, and that views of other stakeholders (e.g., higher education researchers) were not elicited.

\section{A Bottom-up Methodological Framework for Conducting Systematic Literature}

\section{Reviews}

The qualitative research synthesis on the 160 reviews has yielded six methodological stages: background information, search strategy, screening and selection, data extraction, data synthesis, and comments by external parties. The methodological moves of each of these six stages are outlined in Figure 3. The numbers in parentheses in this section represent the number of reviews endorsing each methodological move.

\section{Background Information}

The first methodological stage, background information, comprises five steps, namely state objectives, state research questions/hypotheses, identify a reporting standard, describe credentials of the review team, and establish a working definition for the topic in review. The first step is to state the objectives of the review $(n=5)$. The most common objectives reported in the reviews include conducting a theoretical review (e.g., Crisp \& Cruz, 2009), an empirical review (e.g., Cirsp \& Curz, 2009), and a methodological review (e.g., Jackson \& O’Callagham, 2009). Next, research questions and/or hypotheses $(n=25)$ are mentioned, depending on the nature of the review (a qualitative research synthesis or a meta-analysis, or 
both). The number of research questions and/or hypotheses included in the methodological section ranges from one to six. Having introduced the research questions/hypotheses, reviewers make a claim that the review reported follows a set of reporting standards/methodological frameworks $(n=50)$; some examples of the cited reporting standards are: guidelines of the Association for Medical Education in Europe (AMEE), Assessing the Methodological Quality of Systematic Reviews (AMSTAR), Enhancing Transparency in Reporting the Synthesis of Qualitative Research (ENTREQ), guidelines by the Centre for Reviews and Dissemination and the Evidence for Policy and Practice Information and Co-ordinating Centre (EPPICC), Quorum Review, Meta-analysis of Observational Studies in Epidemiology (MOOSE), and Preferred Reporting Items for Systematic Reviews and Meta-Analysis (PRISMA), Best Evidence Medical Education (BEME) Guide, Cochrane systematic review protocol, and Structured Approach to the Reporting in Healthcare Education of Evidence Synthesis (STORIES). Two methodological frameworks referred to in the reviews are: Arksey and O'Malley (2005) and Kitchenham (2004). Following that, a few reviews include a brief description of the credentials of the review team to enhance credibility of the review process $(n=5)$. The first methodological stage ends with a provision of a working definition of the topic, concept, or construct in review $(n=33)$. The inclusion of a working definition is useful for later stages to construct a list of search terms and inclusion and/or exclusion criteria.

\section{Search Strategy}

This second methodological stage consists of five steps: develop a search strategy, agree on search terms, establish inclusion and/or exclusion criteria, search databases or journal websites, and search manually. 17 systematic literature reviews claim that they consulted a research librarian to develop or give feedback on search strategies for their reviews. These strategies usually address two questions: what search terms to use and which 
databases to search. Three of the systematic literature reviews conducted a pilot study using the search strategies to determine the need for modifications (Durning et al., 2016; Havyer et al., 2016; Naismith \& Cavalcanti, 2015). Regarding search terms, the review team, often in consultation with a research librarian, creates a list of search terms, ranging from two to 19 $(\mathrm{n}=117)$. Usually, these terms are searched individually or in combination using Boolean Operators (e.g., AND, OR, NOT), sometimes with the inclusion of interchangeable terms. Following the agreement on search terms, the review team establishes and agrees on inclusion and/or exclusion criteria prior to conducting literature search $(n=129)$. The three most common considerations are: time frame $(n=109)$, language $(n=88)$, and types of publication (e.g., grey literature) $(\mathrm{n}=30)$. After the search terms are determined, the review team conducts literature search on major research databases $(n=145)$ and/or specific journal websites $(\mathrm{n}=11)$. The most common databases used in the 160 reviews are CINAHL, Cochrane Library, ERIC, JSTOR, MEDLINE, ProQuest, PsycINFO, PubMed, Scopus, Web of Sciences Citation Index. A second round of literature search is then conducted manually, usually by referring to the reference lists of the literature retrieved from the databases or approaching authors for suggestions $(\mathrm{n}=95)$.

\section{Screening and Selection}

The third stage focuses on screening and selecting the studies to be included into a review. This stage includes two levels of screening, followed by the removal of duplicates and resolution of conflicts between reviewers. According to the included reviews, the two levels of screening are conducted independently before discussions. The first level of screening refers to the scanning of titles and abstracts $(n=91)$ while the second level of screening focuses on the full texts $(n=66)$. The purpose of the first-level screening is to narrow down the scope of the studies to be included while the objective of the second-level screening is twofold: (1) to re-examine the relevance of the studies to be reviewed and (2) 
resolve disagreement between reviewers regarding selection. In this process of screening, duplicated copies are removed $(n=13)$. An important step in this methodological stage is to resolve disagreement between reviewers regarding study inclusion $(n=76)$. The most common means to resolve conflicting opinions include discussions and meetings to reach consensus, consult a third (senior) reviewer, and calculate inter-rater reliability/agreement (using Cohen's kappa coefficient or intraclass correlation coefficient). It is also found that a significant number of systematic literature reviews includes quality assessment of selected studies at this stage using existing guidelines e.g., Consolidated Criteria for Reporting Qualitative Research (COREC) checklist, Newcastle-Ottawa scale) (n=60).

\section{Data Extraction}

Selected studies are imported into software for data extraction and synthesis $(n=44)$. Four types of software are used in the 160 reviews: reference management software (e.g., EndNote, RefWorks), qualitative research software (e.g., NVivo), quantitative research software (e.g., SAS, SPSS, Excel, Google Sheets), and review managers (e.g., Covidence, Microsoft Access, RevMan). Next, the imported studies are subject to independent data extraction using a form or checklist which is usually trialed and revised $(\mathrm{n}=98)$. Contingent on the purpose and nature of the review, the most common items included in the data extraction form are: PICO (population, intervention, comparator group, outcome), research aim and design, theoretical framework, findings, and implications. Afterwards, the reviewers would compare their data extraction results and resolve any disagreement using the methods mentioned in Section 3.3, including discussions, seeking third-party opinion, and calculating inter-rater agreement $(n=76)$.

\section{Data Synthesis and Comments by External Parties}

In the fifth stage, in alignment with the research questions and/or hypotheses, the review team conduct qualitative research synthesis $(n=67)$ and/or meta-analysis $(n=40)$ to 
synthesize the data extracted from the studies. It is noted that some of the reviews analyzed do not explicitly describe the synthesis techniques used in the methodology section; in fact, some of them end their methodology section with the data extraction stage, which seems to suggest that findings are reported based on summary (extraction) in lieu of synthesizing findings systematically. Both inductive and deductive approaches are used to conduct qualitative research synthesis. For inductive approaches, an iterative coding process with a constant comparison method is used. For instance, three levels of coding are used in Pitama et al. (2018), namely contextual descriptive coding, pattern coding, and analytical coding, which loosely resemble initial coding, focused coding, and axial coding in GT (Charmaz, 2014). When coding data deductively, the reviewers often adopt an existing conceptual or theoretical framework as the analytical lens (e.g., Kirkpatrick's levels of intervention is used in Reinders et al., 2011) or develop initial categories based on the research questions (e.g., van de Ridder et al., 2015 focuses on feedback process and effects). Similar to the previous two stages (Sections 3.3 and 3.4), any conflicts in data synthesis are resolved, in this case, mostly by reaching a consensus through discussions. As far as meta-analysis is concerned, a wide range of statistical analyses is recorded, including Chi-square test, Fisher's exact test, ttest, ANOVA, Pearson's r correlation, depending on the purpose of the reviews while a number of reviews report only descriptive statistics (e.g., standard deviation (Cook et al., 2013), effect size (Brydges et al., 2015)). Following Arksey and O’Malley (2005), reviewers are recommended, as the final stage in this proposed methodological framework, to consult a third party (who can be experienced reviewers or stakeholders of the topic in review) who can then comment on the rigour of the review process and/or the usefulness of the synthesized data in informing practice and policy; nonetheless, this methodological step is only observed in three systematic literature reviews (Hunt et al., 2011; Jackson \& O’Callagham, 2009; Jeong et al., 2018). 


\section{Discussions and conclusion}

Through the analysis of 160 systematic literature reviews published in international journals in higher education, a six-stage, 20-step methodological framework is put forward. This framework represents the methodological state-of-the art of systematic literature reviews in higher education. While the proposed framework (Figure 3) is almost identical to existing ones, upon a closer examination on the individual steps in each methodological stage (Appendix B), it is revealed that 12 out of the 20 methodological steps are practised by less than $50 \%$ of the systematic literature reviews. All six methodological stages include steps which are reported in less than $50 \%$ of the 160 systematic literature reviews, including "background information" (five out of five steps), "search strategy" (one out of five steps), "screening and selection" (two out of four steps), "data extraction" (one out of three steps), "data synthesis" (two out of two steps), "comments by external parties" (one out of one step). In particular, all methodological steps in stages 1 (background information), 5 (data synthesis), and 6 (comments by external parties) are described in less than $50 \%$ of the systematic literature reviews reviewed. This shows that there is a lack of consensual view amongst higher education researchers pertaining to the essential steps for conducting systematic literature reviews despite the generally agreed-upon methodological stages which are based on existing practices in medical and social sciences research.

This methodological review raises important questions related to the extent of methodological standardization which would meaningfully inform methodological practice. In essence, we ask the question: how can systematic literature review methodologies in higher education be promoted and advanced? To answer this question, one must revisit the discussion at the outset of the article about the nature of an academic discipline. As argued by Tight (2013), a defining feature of a mature academic discipline is its methodological traditions in data collection and analysis. We also note that, higher education, as an academic 
discipline, is highly disconnected because of lack of common language in communicating methodological traditions (Macfarlane, 2012). To develop methodological traditions in systematic literature reviews, a degree of homogeneity, or standardization, in systematic literature reviews methodology is essential. Homogeneous use of jargon is especially crucial in developing a shared language in communicating methodological practices. This can be achieved through the provision of clear operational definitions of jargon. Some of the systematic literature reviews analyzed included the names of the data analysis/synthesis approach which were adopted without explaining what the approach entails both epistemologically and procedurally. Data synthesis approaches mentioned in these syntheses include thematic approach (e.g., Cowen et al., 2016; Haidet et al., 2016), content analysis (e.g., Riesenberg, et al., 2009), bottom-up and top-down coding schemes (e.g., Day et al., 2018), the use of conceptual frameworks (e.g., Wong et al., 2010), and narrative synthesis (e.g., Straus et al., 2013). The absence of jargon explanation is problematic because readers are not given the information about how data were analyzed. For instance, saying that qualitative data were synthesized using content analysis may not be helpful because it does not inform the readers how the content was analyzed; for example, were the data coded inductively or deductively? Mentioning that a thematic approach was adopted is equally undesirable because the question "how were the themes generated?" remains unanswered.

At the same time, we recognize that higher education researchers come from a wealth of disciplinary backgrounds, bringing with them different methodological practices. It is, therefore, important to report in detail each step used to conduct a systematic literature review. Below is a description about how categorization, or coding, was conducted in one of the systematic literature review: "A categorisation was carried out resulting in the following emerging themes: (i) assessment methods, (ii) modes of assessment and (iii) assessment related to given teaching and learning method" (Pereira et al., 2016, p. 1011). Such one- 
sentence description about the coding process can be found in a number of systematic literature reviews in this meta-review. This kind of description does not provide readers with adequate information regarding the coding process. Even though the example seems to suggest that inductive coding was performed, the researchers failed to document how those themes developed. From a grounded theory perspective, those four emerging themes are likely examples of higher-order conceptual categories; nevertheless, the lower-order descriptive categories within each are unknown (Willig, 2013). In other words, vertical and horizontal thematic structure remains nebulous.

As shown from the above, both heterogeneity and homogeneity are needed in advancing systematic literature review methodologies in higher education (Gordon, 2016; Tranfield et al., 2003). It is our hope that this methodological review and framework help to uphold both. The framework acknowledges the need for standardization by synthesizing existing methodological practices into stages and steps. At the same time, it celebrates heterogeneous methodological practices by tabulating the frequency of each methodological stage and step. The calculation of frequencies demonstrates variations in systematic literature review methodology in higher education and advises higher education reviewers to consider including clearer operational definitions and more detailed descriptions in areas where a less consensual view is reached (i.e., methodological stages and steps with low gravity in Appendix B). Essentially, this methodological framework is not a prescription of methodological steps in conducting systematic literature reviews because methodologies vary based on purposes of reviews. Instead, it is our aspiration that this framework serves as materials to instigate methodological dialogues between researchers working in different subfields of higher education, facilitating the development of an academic community (Wenger, 2000).

This study, like any others, is not without limitations. First, 131 of the 160 reviews 
identified come from three "discipline-specific" journals in higher education focused on medical and healthcare education (Tight, 2018, p. 608). We recognize that this has impact on our analysis and conclusions which essentially focus on "discipline-specific" higher education journals, but not those "generic journals" and "topic-specific journals" (Tight, 2018, p. 608). In effect, we understand that we are presenting an analysis of the approaches adopted mostly in medical/health education, which may differ from higher education research as a whole. However, this lopsided distribution of systematic literature reviews reflects the current state of research synthesis in this relatively detached field of higher education which comprises "isolated 'islands"” (Daenekindt \& Huisman, 2020, p. 571). Second, we recognize the influence of our own methodological philosophies and orientations, which are shaped by our own disciplinary backgrounds, which are in social sciences and education. Therefore, our analysis and categorization of methodological stages and steps do not represent the consensual view of the higher education research community, but we attempted to mitigate our bias through regular discussions and referral to established methodological frameworks in other disciplines. Third, our analysis is based on the methodologies reported in the reviews. There is a likelihood that, for some reasons (e.g., because of word limit), reviewers decided to combine some steps under one header and did not mention all sub-steps though they were carried out. For instance, Pereira et al. (2016) did not report on specific steps taken in data synthesis; instead, only the outcome of data synthesis was reported. Finally, a second stage of this review can be a Delphi study in which authors of these 160 systematic literature reviews are contacted and interviewed to probe into their accepted and preferred practices of conducting research synthesis and provide their comments on this bottom-up methodological framework. In so doing, this methodological framework can be refined and made more flexible to represent both baseline and optimal methodological practices of systematic literature reviews, especially concerning the stages and steps which demonstrate diverse 
practices.

\section{References}

Arksey, H., \& O’Malley, L. (2005). Scoping studies: towards a methodological framework. International Journal of Social Research Methodology, 8(1), 19-32. https://doi.org/10.1080/1364557032000119616

Bearman, M., Smith, C. D., Carbone, A., Slade, S., Baik, C., Hughes-Warrington, M., \& Neumann, D. L. (2012). Systematic review methodology in higher education. Higher Education Research \& Development, 31(5), 625-640. https://doi.org/10.1080/07294360.2012.702735

Booth, A., Noyes, J., Flemming, K., Gerhaidus, A., Wahlster, P., van der Wilt, G., Mozygemba, K., Refolo, P., Sacchini, D., Tummers, M., \& Rehfuess, E. (2016). Guidance on choosing qualitative evidence synthesis methods for use in health technology assessments of complex interventions. INTEGRATE-HTA. http://www.integrate-hta.eu/downloads/

Braun, V., \& Clarke, V. (2006). Using thematic analysis in psychology. Qualitative Research in Psychology, 3, 77-101. https://doi.org/10.1191/1478088706qp063oa

Brew, A. (2003). Teaching and research: New relationships and their implications for inquiry-based teaching and learning in higher education. Higher Education Research \& Development, 22(1), 3-18. https://doi.org/10.1080/0729436032000056571

Brydges, R., Hatala, R., Zendejas, B., Erwin, P. J., \& Cook, D. A. (2015). Linking simulation-based educational assessments and patient-related outcomes: A systematic review and meta-analysis. Academic Medicine, 90(2), 246-256. https://doi.org/10.1097/acm.0000000000000549

Charmaz, K. (1996). The search for meanings - grounded theory. In J. A. Smith, R. Harré, \& L. Van Langenhove (Eds.), Rethinking methods in psychology (pp. 27-49). Sage 
publications.

Charmaz, K. (2008). Grounded theory as an emergent method. In S. N. Hesse-Biber \& P. Leavy (Eds.), Handbook of emergent methods (pp. 155-172). The Guilford Press.

Chong, S. W. (2019). A systematic review of written corrective feedback research in ESL/EFL contexts. Language Education and Assessment, 2(2), 57-69. https://doi.org/10.29140/lea.v2n2.138

Chong, S. W., \& Reinders, H. (In Press). Technology-mediated task-based language teaching: A qualitative research synthesis. Language Learning \& Technology, 24(3), 70-86.

Colquhoun, H. L., Levac, D., O'Brien, K. K., Straus, S., Tricco, A. C., Perrier, L., Kastner, M., \& Moher, D. (2014). Scoping reviews: Time for clarity in definition, methods, and reporting. Journal of Clinical Epidemiology, 67(12), 12911294. https://doi.org/10.1016/j.jclinepi.2014.03.013

Cook, D. A., Zendejas, B., Hamstra, S. J., Hatala, R., \& Brydges, R. (2014). What counts as validity evidence? Examples and prevalence in a systematic review of simulation-based assessment. Advances in Health Sciences Education, 19(2), 233-250. https://doi.org/10.1007/s10459-013-9458-4

Cooper, H., \& Hedges, L. V. (1994). The handbook of research synthesis. Russell Sage Foundation.

Crisp, G., \& Cruz, I. (2009). Mentoring College Students: A Critical Review of the Literature between 1990 and 2007. Research in Higher Education, 50, 525-545. https://doi.org/10.1007/s11162-009-9130-2

Daenekindt, S., \& Huisman, J. (2020). Mapping the scattered field of research on higher education. A correlated topic model of 17,000 articles, 1991-2018. Higher Education, 80, 571-587. https://doi.org/10.1007/s10734-020-00500-x

Davies, P. (2000). The relevance of systematic reviews to educational policy and practice. 
Oxford Review of Education, 26(3-4), 365-378. https://doi.org/10.1080/713688543

Durning. S. J., Dong, T., Ratcliffe, T., Schuwirth, L., Artino, A. R., Boulet, J. R., \& Eva, K. (2016). Comparing open-book and closed-book examinations: A systematic review. Academic Medicine, 91(4), 583-599. https://doi.org/10.1097/acm.0000000000000977

Eaves, Y. D. (2001). A synthesis technique for grounded theory data analysis. Journal of Advanced Nursing, 35(5), 654-663. https://doi.org/10.1046/j.1365-2648.2001.01897.x

Evans, J., \& Benefield, P. (2001). Systematic reviews of educational research: does the medical model fit? British Educational Research Journal, 27(5), 527-541. https://doi.org/10.1080/01411920120095717

Ferreira-Valente, A., Monteiro, J. S., Barbosa, R. M., Salgueira, A., Costa, P., \& Costa, M. (2017). Clarifying changes in student empathy throughout medical school: A scoping review. Advances in Health Science Education, 22, 1293-1313. https://doi.org/10.1007/s10459-016-9704-7

Furlan, A. D., Pennick, V., Bombardier, C., \& van Tulder, M. (2009). 2009 updated method guidelines for systematic reviews in the Cochrane Back Review Group. SPINE, 34(18), 1929-1941. https://doi.org/10.1097/brs.0b013e3181b1c99f

Glaser, B. G., \& Strauss, A. L. (1967). The discovery of grounded theory: Strategies for qualitative research. Aldine.

Gordon, M. (2016). Are we talking the same paradigm? Considering methodological choices in health education systematic review. Medical Teacher, 38(7), 746-750.

Gough, D. (2007). Weight of evidence: a framework for the appraisal of the quality and relevance of evidence. Research Papers in Education, 22(2), 213-228. https://doi.org/10.1080/02671520701296189

Gough, D., Thomas, J., \& Oliver, S. (2012). Clarifying differences between review designs and methods. Systematic Reviews, 1(28), 1-9. https://doi.org/10.1186/2046-4053-1-28 
Gough, D., Oliver, S., \& Thomas, J. (2013). Learning from research: Systematic reviews for informing policy decisions: A quick guide. Alliance for Useful Evidence.

Gough, D., Oliver, S., \& Thomas, J. (2017). An introduction to systematic reviews. Sage Publications.

Grant, M. J., \& Booth, A. (2009). A typology of reviews: An analysis of 14 review types and associated methodologies. Health Information and Libraries Journal, 26(2), 91-108. https://doi.org/10.1111/j.1471-1842.2009.00848.x

Hallinger, P. (2013). A conceptual framework for systematic reviews of research in educational leadership and management. Journal of Educational Administration, 51(2), 126-149. https://doi.org/10.1108/09578231311304670

Hallinger, P., \& Kovačević, J. (2019). A bibliometric review of research on educational administration: Science mapping the literature, 1960 to 2018. Review of Educational Research, 89(3), 335-369. https://doi.org/10.3102/0034654319830380

Hargreaves, D. H. (1996). Teaching as a research-based profession: possibilities and prospects. EPPI-Centre

Home. https://eppi.ioe.ac.uk/cms/Portals/0/PDF\%20reviews\%20and\%20summaries/TT A\%20

Havyer. R. D., Nelson, D. R., Wingo, M. T., Comfere, N. I., Halvorsen, A. J., McDonald, F. S., \& Reed, D. A. (2016). Addressing the interprofessional collaboration competencies of the association American medical colleges: A systematic review of assessment instruments in undergraduate medical education. Academic Medicine, 91(6), 865-888. https://doi.org/10.1097/acm.0000000000001053

Hunt. J. B., Bonham. C., \& Jones. L. (2011). Understanding the goals of service learning and community-based medical education: A systematic review. Academic Medicine, 86(2), 246-251. https://doi.org/10.1097/acm.0b013e3182046481 
Jackson, J., \& O’Callaghan, E. (2009) What do we know about glass ceiling effects? A taxonomy and critical review to inform higher education research. Research in Higher Education, 50, 460-482. http://doi.org/10.1007/s11162-009-9128-9

Jeong. D., Presseau, J., ElChamaa, R., Naumann, D. N., Mascaro, C., Luconi, F., Smith, K. M., \& Kitto, S. (2018). Barriers and facilitators to self-directed learning in continuing professional development for physicians in Canada: A scoping review. Academic Medicine, 93(8), 1245-1254. https://doi.org/10.1097/acm.0000000000002237

Kang, E., \& Han, Z. (2015). The efficacy of written corrective feedback in improving L2 written accuracy: A meta-analysis. The Modern Language Journal, 99(1), 1-18. https://doi.org/10.1111/modl.12189

Kelly-Blake, K., Garrison, N. A., Fletcher, F. E., Ajegba, B., Smith, N., Brafford, M., \& Bogdan-Lovis, E. (2018). Rationales for expanding minority physician representation in the workface: A scoping review. Medical Education, 52, 925-935. https://doi.org/10.1111/medu.13618

Khan, K. S., Kunz, R., Kleijnen, J., \& Antes, G. (2003). Five steps to conducting a systematic review. Journal of the Royal Society of Medicine, 96, 118-121. https://doi.org/10.1258/jrsm.96.3.118

Lee, K. (2017). Rethinking the accessibility of online higher education: A historical review. The Internet and Higher Education, 33, 15-23. https://doi.org/10.1016/j.iheduc.2017.01.001

Macfarlane, B. (2012). The higher education research archipelago. Higher Education Research \& Development, 31(1), 129-131. https://doi.org/10.1080/07294360.2012.642846

Mays, N., Roberts, E., \& Popay, J. (2001). Synthesising research evidence. In N. Fulop, P. Allen, A. Clarke, \& N. Black (Eds.), Studying the organisation and delivery of health 
services: Research methods (pp. 188-220). Routledge.

Miake-Lye, I. M., Hempel, S., Shanman, R., \& Shekelle, P. G. (2016). What is an evidence map? A systematic review of published evidence maps and their definitions, methods, and products. Systematic Reviews, 5(28), 1-21. https://doi.org/10.1186/s13643-0160204-x

Moher, D., Liberati, A., Tetzlaff, J., Altman, D. G. (2009). Preferred reporting items for systematic reviews and meta-analysis: The PRISMA statement. Annals of Internal Medicine, 151(4), 264-269. https://doi.org/10.7326/0003-4819-151-4-200908180-00135

Mulrow, C. D. (1994). Rationale for systematic reviews. British Medical Journal, 309(6954), 597-600. https://doi.org/10.1136/bmj.309.6954.597

Munn, Z., Peters, M. D. J., Stern, C. et al. (2018). Systematic review or scoping review? Guidance for authors when choosing between a systematic or scoping review approach. BMC Medical Research Methodology, 18, 143. https://doi.org/10.1186/s12874-018-0611-x

Naismith. L. M., \& Cavalcanti. R. B. (2015). Validity of cognitive load measures in simulation-based training: A systematic review. Academic Medicine, 90(11), S24-S35. https://doi.org/10.1097/acm.0000000000000893

Newman, M., \& Gough, D. (2020). Systematic reviews in educational research: Methodology, perspectives and application. In O. Zawacki-Richter, M. Kerres, S. Bedenlier, \& M. Bond (Eds.), Sysetmatic reviews in educational research: Methodolgy, perspectives and application (pp. 3-22). Springer.

Nowell, L. S., Norris, J. M., White, D. E., \& Moules, N. J. (2017). Thematic analysis: Striving to meet the trustworthiness criteria. International Journal of Qualitative Methods, 16, 1-13. https://doi.org/10.1177/1609406917733847

O'Flaherty, J., \& Phillips, C. (2015). The use of flipped classrooms in higher education: A 
scoping review. Internet and Higher Education, 25, 85-95.

https://doi.org/10.1016/j.iheduc.2015.02.002

Petticrew, M., \& Roberts, H. (2008). Systematic reviews in the social sciences: A practical guide. Blackwell.

Pham, M. T., Rajić, A., Greig, J. D., Sargeant, J. M., Papadopoulos, A., \& McEwen, S. A. (2014). A scoping review of scoping reviews: advancing the approach and enhancing the consistency. Research Synthesis Methods, 5(4), 371-385.

https://doi.org/10.1002/jrsm.1123

Pitama, S. G., Palmer ,S .C., Huria, T., Lacey, C., \& Wilkinson, T. (2018). Implementation and impact of indigenous health curricula: A systematic review. Medical Education, 52, 898-909. https://doi.org/10.1111/medu.13613

Reinders, M. E., Ryan, B. L., Blankenstein, A. H., van der Horst, H. E., Stewart, M. A., \& van Marwijk, H. W. J. (2011). The effect of patient feedback on physicans' consultation skills: A systematic review. Academic Medicine, 86(11), 1426-1436.

https://doi.org/10.1097/acm.0b013e3182312162

Strauss, A. L., \& Corbin, J. M. (1990). Basics of qualitative research: grounded theory procedures and techniques. Sage Publications.

Tight, M. (2004). Research into higher education: An a-theoretical community of practice? Higher Education Research \& Development, 23(4), 395-411. https://doi.org/10.1080/0729436042000276431

Tight, M. (2013). Discipline and methodology in higher education research. Higher Education Research \& Development, 32(1), 136-151. https://doi.org/10.1080/07294360.2012.750275

Tight, M. (2018). Higher education journals: Their characteristics and contribution. Higher Education Research \& Development, 37(3), 607-619. 
https://doi.org/10.1080/07294360.2017.1389858

Tight, M. (2019). Systematic reviews and meta-analyses of higher education research. European Journal of Higher Education, 9(2), 133-152. https://doi.org/10.1080/21568235.2018.1541752

Tranfield, D., Denyer, D., \& Smart, P. (2003). Towards a methodology for developing evidence- informed management knowledge by means of systematic review. British Journal of Management, 14(3), 207-222. https://doi.org/10.1111/1467-8551.00375

Tricco, A. C., Lillie, E., Zarin, W., O’Brien, K., Colquhoun, H., Kastner, M., Wilson, K. (2016). A scoping review on the conduct and reporting of scoping reviews. BMC Medical Research Methodology, 16(1), 15. https://doi.org/10.1186/s12874-016-0116-4

Välimaa, J. (1998). Culture and identity in higher education research. Higher Education, 36, 119-138.

Van de Ridder, J. M., McGaghie, W. C., Stokking, K. M., \& ten Cate O. T. (2015). Variables that affect the process and outcome of feedback, relevant for medical training: A metareview. Medical Education, 49(7), 658-673. https://doi.org/10.1111/medu.12744

Van Tulder, M., Furlan, A., Bombardier, C., Bouter, L., \& Group, E. B. of the C. C. B. R. (2003). Updated method guidelines for systematic reviews in the cochrane collaboration back review group. Spine, 28(12), 1290-1299. https://doi.org/10.1097/01.brs.0000065484.95996.af

Wenger, E. (2000). Communities of practice and social learning systems. Organization, 7 , 225-246. https://doi.org/10.1177/135050840072002 


\section{Table 1}

Breakdown of Systematic Literature Reviews in Higher Education by Journal

\begin{tabular}{|c|c|}
\hline & TOTAL \\
\hline Medical Education & 63 \\
\hline Academic Medicine & 56 \\
\hline Advances in Health Sciences Education & 12 \\
\hline Higher Education Research \& Development & 6 \\
\hline Assessment and Evaluation in Higher Education & 4 \\
\hline Internet and Higher Education & 4 \\
\hline Studies in Higher Education & 3 \\
\hline International Journal of Doctoral Studies & 2 \\
\hline International Journal of Sustainability in Higher & 2 \\
\hline Education & \\
\hline Research in Higher Education & 2 \\
\hline Accounting Education & 1 \\
\hline Higher Education Quarterly & 1 \\
\hline Journal of College Student Development & 1 \\
\hline Journal of English for Academic Purposes & 1 \\
\hline Journal of Studies in International Education & 1 \\
\hline Teaching in Higher Education & 1 \\
\hline Active Learning in Higher Education & 0 \\
\hline Community College Review & 0 \\
\hline Higher Education & 0 \\
\hline Higher Education Policy & 0 \\
\hline
\end{tabular}




\begin{tabular}{l|c} 
Journal of Higher Education & 0 \\
Journal of Higher Education Policy and Management & 0 \\
Journal of Hispanic Higher Education & 0 \\
Minerva & 0 \\
Quality of Higher Education & 0 \\
Research Evaluation & 0 \\
Review of Higher Education & 0 \\
Tertiary Education and Management & 0 \\
\hline TOTAL & 160 \\
\hline
\end{tabular}

\section{Table 2}

Breakdown of Systematic Literature Reviews in Higher Education by Year

\begin{tabular}{c|c}
\hline Year & $\begin{array}{c}\text { The number of systematic literature review } \\
\text { published }\end{array}$ \\
\hline $2019^{4}$ & 2 \\
2018 & 15 \\
2017 & 16 \\
2016 & 20 \\
2015 & 18 \\
2014 & 11 \\
2013 & 16 \\
2012 & 8 \\
2011 & 10 \\
2010 & 11 \\
\hline
\end{tabular}
2019.

${ }^{4}$ When the search was conducted in October 2018, these two reviews were published online, which were later assigned into an issue in 


\begin{tabular}{l|l}
2009 & 12 \\
2008 & 4 \\
2007 & 11 \\
2006 & 2 \\
2003 & 1 \\
2002 & 2 \\
2000 & 1 \\
\hline TOTAL & 160 \\
\hline
\end{tabular}

\section{Figure 1}

Breakdown of Systematic Literature Reviews in Higher Education by Locations

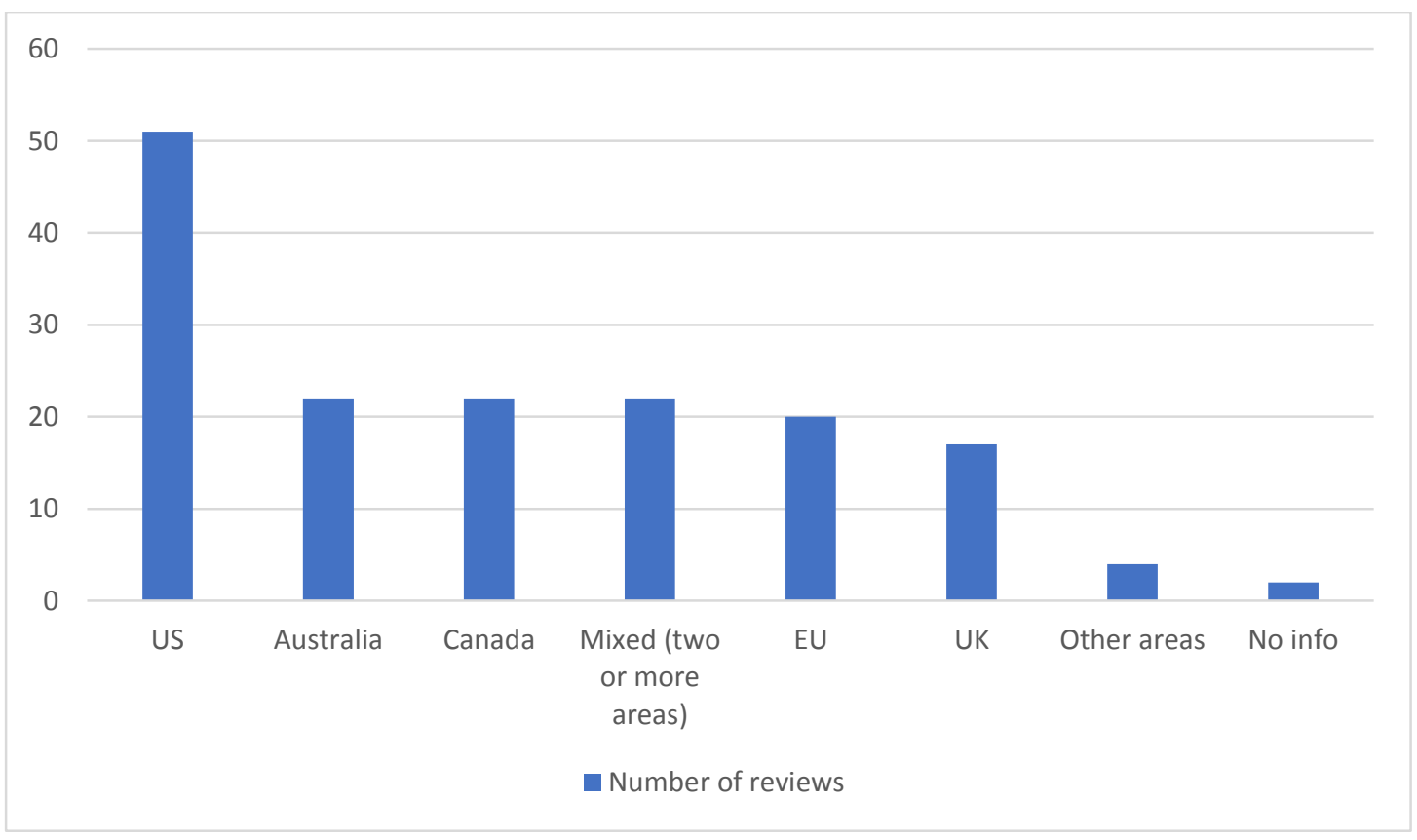

Table 3

A Summary of the Scoping Review Methodology Framework by Arksey and O'Malley (2005)

Step $1 \quad$ Identify the research question(s) that will guide the proceeding search 


\begin{tabular}{ll}
\hline Step 2 & Identify relevant studies based on the predetermined search strategy \\
Step 3 & Develop exclusion and inclusion criteria for study selection \\
Step 4 & Chart the key items of information obtained from primary studies being \\
& reviewed (authors, intervention types, study aims, methodology, etc.) \\
Step 5 & Collate, summarize and report the results and provide a narrative \\
& account of existing literature through basic numerical analysis or \\
& Consult with stakeholders to enhance the review and make the results \\
Step 6 & more useful
\end{tabular}

\section{Figure 2}

\section{PRISMA Flow Chart for Study Selection}

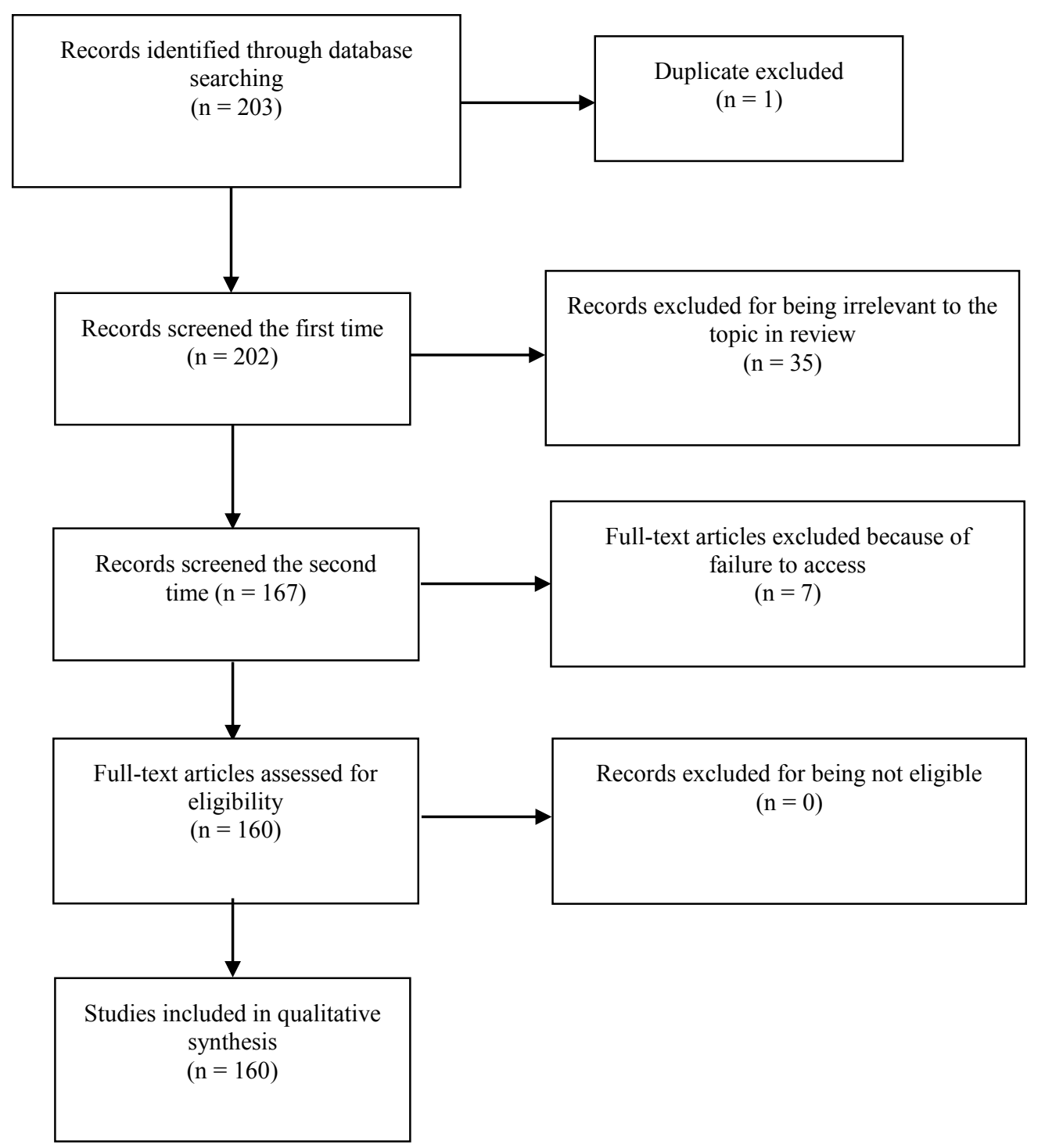


Table 4

Steps Taken to Synthesise Data

Step Nowell et al.'s (2017) Description of step

TA framework

$1 \quad$ Familiarising with data $\quad$ Read the methodology section line-by-line and underline key phrases to get fresh insight from the data.

2 Generating initial codes Generated a list of in-vivo phrases and developed it into shorter code phrases that best summarize the methodological moves made.

$3 \quad$ Identifying themes

Reduced the phrases by grouping similar code phrases together to form the preliminary themes.

$4 \quad$ Reviewing themes

Constant comparison was made between codes and themes for similarities and relationships between themes. Identified the sub-themes, which are characteristics and properties of the identified themes. 
5 Defining and naming Made linkages among themes and subthemes themes. Existing literature was referred to when determining relationships between themes. Distinctive methodological stages (themes) and steps (sub-themes) were defined and named at the end of this stage.

Reported the methodological framework following the identified themes and subthemes. 
Figure 3

A Bottom-up Methodological Framework for Conducting Systematic Literature Reviews

\begin{tabular}{|c|c|c|}
\hline Background Information & Search strategy & Screening and selection \\
\hline $\begin{array}{l}\text { State objectives } \\
\text { Describe credentials of the team } \\
\text { Identify a reporting standard } \\
\text { Establish a working definition }\end{array}$ & $\begin{array}{l}\text { Develop search strategy } \\
\text { Establish inclusion/exclusion criteria } \\
\text { Search databases/journal websites } \\
\text { Search manuallv }\end{array}$ & Remove duplicates \\
\hline Comments by external parties & Data synthesis & Data extraction \\
\hline Consult experts and/or stakeholders & $\begin{array}{l}\text { Conduct qualitative synthesis and/or meta- } \\
\text { analysis } \\
\text { Resolve conflicts }\end{array}$ & $\begin{array}{l}\text { Import studies into software } \\
\text { Extract data using a form } \\
\text { Resolve conflicts }\end{array}$ \\
\hline
\end{tabular}

